\title{
A Study on the Impact of Psychological Capital on Organizational Identification
}

\author{
(With Special reference to Sales Persons in C grade Cargills Food City Outlets in Colombo \\ District)
}

\author{
R.M.M.C. Rajapaksha \\ Department of Management Sciences \\ Faculty of Management \\ Uva Wellassa University \\ Badulla, Sri Lanka \\ medanichanchala123@gmail.com
}

\author{
L.D. Kalyani \\ Department of Business Management \\ Faculty of Management Studies \\ University of Sabaragamuwa \\ Pambahinna, Sri Lanka \\ kal@mgt.sab.ac.lk
}

\section{DOI: $10.31364 / \mathrm{SCIRJ} / \mathrm{v} 8.112 .2020 . P 1220824$ \\ http://dx.doi.org/10.31364/SCIRJ/v8.i12.2020.P1220824}

\begin{abstract}
In today's context human resource is considered as a valuable resource for any business organization as business organizations are operating in a very competitive environment. The study was aimed at investigating the impact of Psychological Capital and its dimensions (Self-efficacy, Optimism, Hope and Resilience) on Organizational Identification of sales persons of $\mathrm{C}$ grade Cargills Food City outlets in Colombo District Sri Lanka. There were 116 sales persons in $\mathrm{C}$ grade Cargills Food City outlets in Colombo district. The researcher considered entire population for the study as it was considered census method for collecting data. Simple regression analysis and multiple regression were performed to investigate the impact of the variables interested. Pertaining to the previous research findings, the current study also brought evidence to a significant impact of Psychological Capital, Self-efficacy, Hope and Resilience on Organizational Identification. In contrast to the previous research findings, this study highlighted no any impact of optimism on organizational identification. Further, future researchers are advised to do the studies by considering managers or the immediate supervisors' perspectives about the organizational identification of sales persons, using multiple data collection methods instead of using only self - administrated questionnaires.
\end{abstract}

Index Terms - Hope, Optimism, Organizational Identification, Psychological Capital, Resiliency, Self - efficacy

\section{INTRODUCTION}

According to the study of Aktas (2014), "Person- environment fit is a concept that has attracted the management scholar's interest in recent years, since obtaining person- environment fit in organization is crucial for retaining a flexible work force" (p.290). In the same study, it has emphasized those individuals that are living in collectivist societies should bear in mind that the values of the organization they work for has great importance in their satisfaction and, therefore, selecting the right organization that fits their values is the key to having more positive attitudes toward their work. According to the above literature, it can be used the concept of organizational identification to identify whether the employees choose right organization to work. Therefore, in this study it was used organizational identification as the Dependent Variable (DV). According to Murray, Duncan, Pontes and Griffiths (2015) organizational identification refers to person's sense of belonging to the place where they work for. If there is an organizational identification within the members of an organization, it will lead to a range of desirable attitudes and behaviours (Murray et al., 2015). Further, organizational identification has important implications for organizational behaviours and the overall organizational effectiveness (Gonzalez \& Chakraborty, 2012).

In the era of globalization and utmost competition, organizations survive and thrive on optimal utilization of their human resources (Seval \& Carner, 2015 as cited in Gupta, Shaheen \& Reddy, n.d.). Gupta et al., n.d. believes that "psychological capital is a critical personal resource which facilitates human resource in the completion and achievement of official targets" (p.2). Moreover, psychological capital has given much attention in the recent past as a new approach to enhance the job performance of the employees (as cited in Kappagoda, Othman \& Alwis, 2014). "Psychological capital (PsyCap) is a positive psychological state-like characteristic involving confidence to succeed at challenging tasks (selfefficacy), making personal attributions for positive outcomes (optimism), persisting toward goals and changing path when necessary (hope) and bouncing back from adversity (resiliency)" (Luthans, Youssef \& Avolio, 2007 as cited in Gruman \& Saks, 2016, p.231). According to the above definition, there are four dimensions in psychological capital namely self-efficacy, optimism, hope and resilience. It was expected to find out the impact of psychological capital and its dimensions on organizational identification as per the 
conceptual framework developed by the author (See Figure 1). Although there are plenty of researches regarding psychological capital and the organizational identification separately, the researches regarding both the topics at the same time lack in the past literature. According to the scholars (Luthans et al., 2007; Norman et al., 2010), numerous studies have investigated the relationship between psychological capital and employee attitudes ...etc., but the process of identification and its association with psychological capital are rarely investigated ( as cited in Tuzun, Cetin \& Basim, 2018). Psychological capital is emerging as a viable pathway to understand and encourage optimal human performance in the work place (Luthans et al., 2007 as cited in Rehman et al., 2017). According to the Kharas (2012), if there is an organizational identification within an employee with regard to the place where they work, it can be obtained maximum benefit from such employee to the organization. Therefore, according to that interpretations it can be identified that both the concepts are driven in to the same direction which can gain maximum benefit to the relevant organization. In addition to that if the employees' psychological capital get reduce, it will cause to decrease their organizational identification (Robinson, 1997 as cited in Rani, Arain, Kumar \& Shaikh, 2017). Moreover, Tuzun et al., (2018) found that "psychological capital has a positive effect on job performance and that work unit identification enhances employees' level of psychological capital" (p.164).

\section{Conceptual Framework}

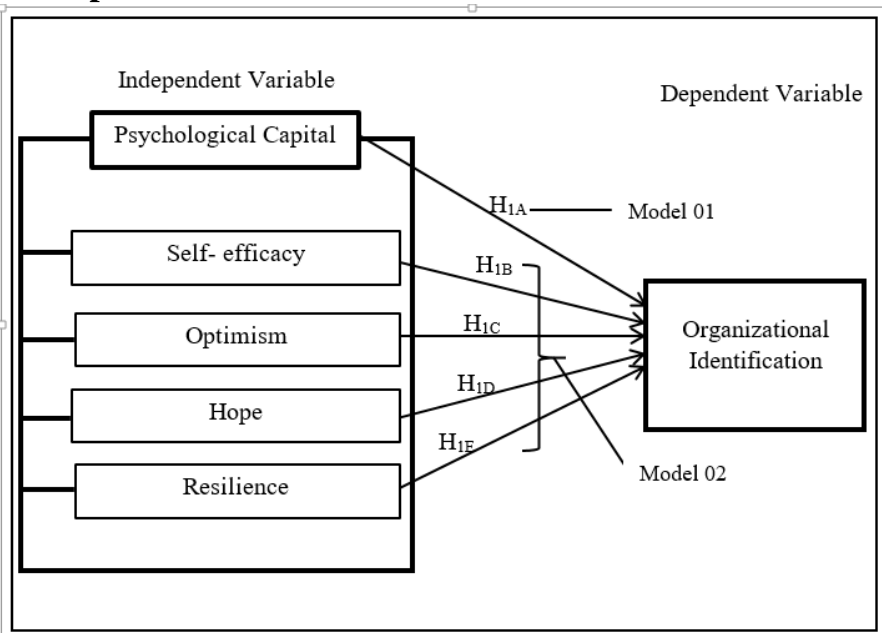

Fig. 1. Conceptual Framework

(Developed by the author based on the literature)

\section{Research Problem}

In recent reviews of literature regarding organizational identification, it has emphasized the importance of doing researches on this matter as it is an under- researched area at the moment (He \& Brown, 2013 as cited in He et al., 2015). The study by Ekmekci and Casey (2011) suggested future researchers to do more researches regarding organizational identification of contingent workers by using other variables. According to Perera (2003), there are lack of published empirical studies on the supermarket industry in Sri Lanka. Therefore, researcher selected supermarket industry to do the investigation. The researcher expected to find out whether there is an organizational identification among the sales persons of $\mathrm{C}$ grade Cargills Food City outlets in Colombo district and is it affected by psychological capital including self - efficacy, hope, optimism and resilience of them. As per the researcher's observations, there is a high turnover of sales persons of $\mathrm{C}$ grade Cargills Food City outlets. Thus, In addition to the above literature and the observations, the researcher conducted a preliminary investigation.

TABLE I. Mean Values

\begin{tabular}{|c|c|}
\hline $\begin{array}{c}\text { Expected Organizational } \\
\text { Identification }\end{array}$ & $\begin{array}{c}\text { Actual Organizational } \\
\text { Identification }\end{array}$ \\
\hline 3 & 2.8 \\
\hline
\end{tabular}

Source: Preliminary Survey (2017)

According to Table I, the responses provided by the 20 respondents, actual organizational identification level is 2.8. Therefore, it is obvious that there is a gap between expected and actual organizational identification in the year 2017 based on the Anaza (2015) five point Likert scale on organizational identification.

By considering above literature, observations and results of the preliminary investigation, it can be identified that there is a growing problem to investigate about the organizational identification within the selected organizational context and therefore the researcher formulated the research problem for the study as follows:

"Why there is low organizational identification of sales persons in $C$ grade Cargills Food City outlets in Colombo district?"

\section{Hypotheses of the Study}

Organizations are developing strategies to attract and retain their employees in the organization (Dick et al., 2007 as cited in Ekmekci \& Casey, 2011) and those strategies are largely grounded in the assumption that the employees attract and retain in the organization, if only their individual values match with the organizational identification (Coldwell et al., 2008 as cited in Ekmekci \& Casey, 2011). Tosti- Kharas (2012), in his study found that continued organizational identification positively related to the psychological well- being in his selected samples. "For people who have lost their jobs, maintaining psychological well- being is one of the central challenges to daily existence" (Jahoda, 1982; Mckee- Ryan et al., 2005 as cited in Tosti- Kharas, 2012, p.831). According to Boros (2008), organizational identification can yield desirable results for both the organization and the individuals. Therefore, it can be decided that if there is psychological capital within the employees of an organization there should be desirable results such as positive employee behaviours. When referring above literature, it could be identified that there is a relationship between psychological capital and the organizational identification. Therefore, with the aim of find whether there is an impact of psychological capital and its dimensions (self - efficacy, optimism, hope, resiliency) on organizational identification, the following hypotheses can be proposed to this study:

$\mathrm{H}_{1 \mathrm{~A}}$ - There is an impact of psychological capital on organizational identification of sales persons in $\mathrm{C}$ grade Cargills Food City outlets in Colombo district

$\mathrm{H}_{1 \mathrm{~B}}$ - There is an impact of self- efficacy on organizational identification of sales persons in $\mathrm{C}$ grade Cargills Food City outlets in Colombo district 
$\mathrm{H}_{1 \mathrm{C}}$ - There is an impact of optimism on organizational identification of sales persons in $\mathrm{C}$ grade Cargills Food City outlets in Colombo district

$\mathrm{H}_{1 \mathrm{D}}$ - There is an impact of hope on organizational identification of sales persons in $\mathrm{C}$ grade Cargills Food City outlets in Colombo district

$\mathrm{H}_{1 \mathrm{E}}$ - There is an impact of resilience on organizational identification of sales persons in $\mathrm{C}$ grade Cargills Food City outlets in Colombo district.

\section{METHODOLOGY}

This study is focused on the philosophy of positivism because the researcher conducts an objective research study which is independent of social factors. Also, as this study dealt with numerical values, in its collection and analyzing process, the researcher used quantitative method for the present study. As this study is a quantitative study based on positivist paradigm, the researcher is going to find out whether there is an impact of psychological capital on organizational identification by testing already developed hypotheses. Therefore, this research study follows the deductive approach.

\section{Population}

The population which is selected by the researcher is manageable as there are only 116 sales persons in $\mathrm{C}$ grade Cargills Food City outlets in Colombo district to get for the population. Hence, the researcher used census method for collecting data from the entire population. Moreover, because of that reason, the generalizability of the results of the study is high. The researcher developed a questionnaire to collect primary data from the selected population. Those selfadministered questionnaires were distributed among all the sales persons of $\mathrm{C}$ grade Cargills Food City outlets in Colombo district as the researcher used census method for collecting data. Total number of sales persons in $\mathrm{C}$ grade Cargills Food City outlets is 116 and only 92 questionnaires were received from the distributed questionnaires.

\section{Validity}

Validity of the instrument of psychological capital is already tested by the authors and it is validated (Saunders et al., 2009). According to Ashforth and Mael (1992), validity of the organizational identification instrument is 0.83 and therefore, the validity of the instrument can be identified as good. (as cited in Anaza, 2015).

\section{Reliability}

It is measured psychological capital by using an instrument developed for measuring psychological capital for Thai employees. It is consisted with four main variables called selfefficacy, optimism, hope and resilience and 24 items in total. The total reliability of this construct is high and recorded as 0.95 (Sapyaprapa et al., 2013). The dimensions of psychological capital self - efficacy, optimism, hope and resilience are recorded reliability values of $0.87,0.80,0.84$ and 0.87 respectively (Luthans et al., 2007 as cited in Sapyaprapa et al., 2013). The reliability value of organizational identification is 0.85 (Ashforth \& Mael, 1992 as cited in Anaza, 2015).

\section{DATA ANALYSIS AND PRESENTATION}

The researcher collected data from the sales persons of $\mathrm{C}$ grade Cargills Food City outlets in Colombo district. As the researcher followed census method for collecting data, the questionnaires were distributed to the entire population and the total number of sales persons in $\mathrm{C}$ grade Cargills Food City outlets in Colombo district is 116 . The researcher received 92 questionnaires and therefore, the response rate was $79 \%$.

\section{Correlation Analysis}

TABLE II. CORRELATION ANALYSIS

\begin{tabular}{|l|c|c|}
\hline \multicolumn{1}{|c|}{ Variable } & $\begin{array}{c}\text { Correlation } \\
\text { Coefficient }(\mathrm{r})\end{array}$ & P Value \\
\hline Self-efficacy & 0.473 & 0.000 \\
\hline Optimism & 0.373 & 0.000 \\
\hline Hope & 0.415 & 0.000 \\
\hline Resilience & 0.437 & 0.000 \\
\hline
\end{tabular}

Source: Census Data (2018)

According to Table II all the dimensions of psychological capital were positively correlated with organizational identification as with the Pearson correlation coefficient of 0.473 with self-efficacy, 0.373 with optimism, 0.415 with hope and 0.437 with resilience significantly. As all Pearson correlation coefficients are between 0.5 and 0.3 , there is a low degree of positive correlation between each pair of variables under $95 \%$ confidence level.

\section{Test of Normality}

\section{TABLE III. TEST OF NORMALITY}

\begin{tabular}{|c|c|}
\hline Dependent Variable & P Value (KS Test) \\
\hline Organizational Identification & 0.077 \\
\hline
\end{tabular}

Source: Census Data (2018)

According to the results, the output $\mathrm{P}$ value is 0.077 . Since, the output $\mathrm{P}$ value is greater than critical $\mathrm{P}$ value $(0.05)$, there aren't enough evidence to reject $\mathrm{H} 0$ (H0: Organizational Identification follows a normal distribution, H1: Organizational Identification does not follow a normal distribution). Therefore, with $95 \%$ confidence, the researcher could conclude that Organizational Identification follows a normal distribution.

\section{Regression Analysis}

TABLE IV. REGRESSION OUTPUT

\begin{tabular}{|c|c|l|c|c|}
\hline $\begin{array}{c}\text { Type of } \\
\text { Analysis }\end{array}$ & $\begin{array}{c}\text { Mo } \\
\text { del }\end{array}$ & Variable & B & P Value \\
\hline $\begin{array}{c}\text { Simple } \\
\text { Regressi } \\
\text { on } \\
\text { Analysis }\end{array}$ & 01 & $\begin{array}{l}\text { (Constant) } \\
\text { al Capital }\end{array}$ & 1.175 & 0.000 \\
\hline $\begin{array}{c}\text { Multiple } \\
\text { Regressi } \\
\text { on }\end{array}$ & 02 & (Constant) & 0.737 & 0.000 \\
\cline { 3 - 5 } & & Self-efficacy & 0.198 & 0.028 \\
\cline { 3 - 5 } & Optimism & 0.077 & 0.393 \\
\hline
\end{tabular}




\begin{tabular}{|l|l|l|l|l|}
\hline Analysis & & Hope & 0.318 & 0.000 \\
\cline { 3 - 5 } & Resilience & 0.388 & 0.000 \\
\cline { 2 - 4 } & \multirow{4}{*}{03} & (Constant) & 0.787 & 0.017 \\
\cline { 3 - 4 } & Self-efficacy & 0.220 & 0.014 \\
\cline { 3 - 4 } & Hope & 0.316 & 0.000 \\
\cline { 3 - 5 } & & Resilience & 0.427 & 0.000 \\
\hline
\end{tabular}

TABLE V. TEST OF MULTICOLLINEARITY

\begin{tabular}{|l|c|}
\hline \multicolumn{1}{|c|}{ Variables } & VIF Value \\
\hline Self-efficacy & 1.342 \\
\hline Hope & 1.279 \\
\hline Resilience & 1.089 \\
\hline
\end{tabular}

Source: Census Data (2018)

TABLE VI. TEST OF MULTICOLLINEARITY

\begin{tabular}{|c|c|c|}
\hline Type of Analysis & R Square & $\begin{array}{c}\text { Adjusted R } \\
\text { Square }\end{array}$ \\
\hline Model 01 & 0.506 & - \\
\hline Model 03 & - & 0.409 \\
\hline
\end{tabular}

Source: Census Data (2018)

Regression analysis is used to assess the strength of relationship between a numerical dependent variable and one or more numerical independent variable (Saunders et al., 2009). As the researcher tested the impact of the independent variable and its dimensions on organizational identification, it was used simple regression analysis and multiple regression analysis for the study. Multicollinearity poses a problem only for multiple regressions. Normally multiple regression consists with two or more predictor variables. Multicollinearity exists when there is a strong correlation between two or more predictor variables in regression model (Field, 2009). According to Field (2009) SPSS produces various collinearity diagnostics, one of which is the Variance Inflation Factor (VIF) and VIF indicates whether independent variable has a strong linear relationship with the other independent variables. VIF value should be less than $10(\mathrm{VIF}<10)$. Then it can be concluded that particular model is not suffering from multicollinearity effect. As all the VIF values of dimensions of the independent variable of the selected model is less than 10, it can be concluded that there is no multicollinearity issue in the present study (See Table V). Table IV shows the output of the simple regression analysis and multiple regression analysis which is done under the enter method and backward elimination method respectively. Constant term or the $\beta_{0}$ is 1.175. This emphasis that, it is expected to have 1.175 units of organizational identification when there is no effect of psychological capital. Moreover, 0.797 is the regression coefficient of the psychological capital and it means that organizational identification can be increased by 0.797 units, if psychological capital increases by 1 unit while keeping other factors as constant. Results of multiple regression analysis show that constant term or the $\beta 0$ is 0.787 . This emphasizes that, it is expected to get 0.787 units of organizational identification, when there is no effect of any variables. The regression coefficient of self - efficacy is 0.220 and that means organizational identification can be increased by 0.220 units, if self - efficacy increases by 1 unit while keeping other factors as constant. If hope increases by 1 unit, it could be able to increase organizational identification by 0.316 . In the same manner organizational identification can be increased by 0.427 units, if resilience increases by unit while keeping other factors as constant as the regression coefficient of resilience takes 0.427. (See Table IV).

As per the Table VI, 50.6\% variation of the organizational identification can be explained through the fitted model 01. Therefore remaining $49.4 \%$ changes of organizational identification can't be explained through the fitted regression line. Moreover, adjusted R square value (0.409) emphasizes that $40.9 \%$ of the variation of organizational identification is going to be explained by self - efficacy, hope, resilience of sales persons of $\mathrm{C}$ grade Cargills Food City outlets in Colombo district. Therefore, remaining $59.1 \%$ changes of dependent variable can't be explained through dimensions of psychological capital and there might be other factors that can be explained this variation.

\section{Discussion}

The present study was conducted to investigate the impact of psychological capital and its dimensions on organizational identification of sales persons in Cargills Food City outlets in Colombo district. Findings of the study revealed that except optimism, psychological capital and its other dimensions impact on organizational identification. The dimension of psychological capital optimism has no impact on organizational identification in the selected context. Although there are many researches regarding psychological capital and organizational identification separately, the researches which found the relationship and impact of the psychological capital and the organizational identification are very few in number. Tuzun et al., (2008) have done the research study regarding improving job performance through identification and psychological capital. They could identify that different organizational identification forces such as organizational commitment, job satisfaction, citizenship behaviours, job performance...etc. Further, they found psychological capital has positive relationship with all those forces and it means that psychological capital has positive relationship with organizational identification. In Tuzun et al. (2008) studies, they have found the impact of psychological capital on four organizational identification forces namely, identification with supervisor, identification with coworker, identification with work unit and identification with occupation. According to the results of the Tuzun et al., studies (2008), Psychological Capital has a significant effect on identification with the supervisor $(\beta=0.59, \mathrm{P}<0.001)$, Psychological Capital has a significant effect on identification with work unit $(\beta=0.34, \mathrm{P}<$ 0.001). Moreover, according to the present study of the researcher, it has identified that there is a positive impact of psychological capital on organizational identification $(\beta=$ $0.797, \mathrm{P}<0.000$ ). Therefore, the findings of the current study are again proved. Moreover, the researcher accepted the first hypothesis and further concluded to improve organizational identification by increasing the psychological capital of the sales persons. In addition to that according to the results of the study, the dimension of the psychological capital optimism is insignificant. According to $\mathrm{Xu}$, Liu and Chung (2016), optimism refers to a positive explanation style of good and bad events. The general observations about the sales persons provide the evidences for that. Most of the sales persons have no clear expectations about their future career. And also they 
show the negative feelings on others and have no any innovative ideas about the situations that they have to deal with.

\section{CONCLUSION}

The overall objective of this study is to find out whether there is an impact of psychological capital and its dimensions on organizational identification of sales persons in $\mathrm{C}$ grade Cargills Food City outlets in Colombo district. According to the observations of the researcher as well as the preliminary study were supported to identify the lower level organizational identification of sales persons as an issue. Therefore, it is supported to confirm the research problem of the current study. The researcher developed the conceptual framework after referring existing literature for the present study to examine the impact of independent variable (psychological capital) and its dimensions (self-efficacy, optimism, hope and resilience) on dependent variable (organizational identification). The researcher used both simple and multiple regression analysis when testing the hypotheses which has built according to the objectives of the present study. Before testing the regression analysis, the researcher ensured the reliability and validity measures. Moreover, the correlation test was also performed. Even though there was no any significant impact to be identified between optimism and OI. Finally the present study concluded that psychological capital, self-efficacy, hope, and resilience are significantly impact on OI and optimism was not found to be impacted on OI with special reference to the sales persons of $\mathrm{C}$ grade Cargills Food City outlets in Colombo district. Hence, the researcher has successfully achieved four specific objectives of the study.

\section{MANAGERIAL IMPLICATIONS AND FUTURE RESEARCH DIRECTIONS}

According to the results of the study, it is proved that there is an impact of psychological capital on organizational identification and hence, it should be taken necessary actions for enhancing organizational identification by influencing to the psychological capital and its dimensions of sales persons before, experiencing the negative consequences of lack of organizational identification such as high employee turnover, low commitment of employees...etc. If it is considered psychological capital as a core construct which can be influenced to have the positive outcomes such as organizational identification, the psychological resource theory provides the importance of individual resources such as self - efficacy, hope etc. (Hobfoll, 2002 as cited in Luthans, Youssef \& Avolio, 2007). Also, psychological capital is influenced by social cognitive theory. According to that the agentic, cognitive, developmental capacity of four dimensions of psychological capital are helped in one's positive outcomes such as motivation, perseverance, retaining in an organizations etc. (Carolyn, Youssef \& Luthans, 2013). Moreover, Organization should consider offering individual development and training programmes for sales persons to enhance their level of selfefficacy, hope and resilience of psychological capital. Organizations should introduce organizational policies and managerial practices which enhances the organizational identification. Further, effective public relations activities which are affected to self-efficacy, hope and resilience, may help employees to discover different organizational identification forces as mentioned in the above chapter and applying them may cause to enhance the overall organizational identification.

For the future researchers, it is better to investigate other factors which are affecting to organizational identification other than psychological capital, self-efficacy, hope and resilience. Also it can be suggested that to examine psychological capital and its dimensions in other similar occupational contexts to measure the significance of the model. In this study, organizational identification has been measured only in sales persons' perspective. It is suggested for the future studies to measure sales persons' organizational identification through the management or the direct supervisors of them. It will help to gain findings more significantly and researchers can measure employees exact organizational identification with psychological capital. The researcher used only selfadministrated questionnaire to gather data, if it can be used multiple methods to gather data, it may help to explore new knowledge in the research context.

\section{REFERENCES}

[1] Aktas, M. (2014). Moderating effect of idiocentrism an allocentrism on person- organization person- job fit and work attitudes relationships. Contemporary Hospitality Management, 290-305.

[2] Anaza, N. A. (2015). Realations of fit and organizational identification to employee- customer identification. Managerial Psychology, 925-939.

[3] Boros, S. (2008). An exploratory study in to organizational repatriates' emotional support network. Journal of Cross Cultural and Strategic Management, 645 - 668.

[4] Carolyn, M., Morgan, Y., \& Luthans, F. (2013). Psychological capital theory: Toward a positive holistic model. Advances in Positive Organizational Psychology, 145 - 166.

[5] Ekmecki, O., \& Casey, A. (2011). Computer simulation exploring organizational identification for contingent workers. Commerce and Management, 279-298.

[6] Field, A. (2009). Discovering Statistics Using SPSS. SAGE Publication.

[7] Gonzalez, J. A., \& Chakraborty, S. (2012). Image and similarity: An identity orientaton perspective to organizational identification. Commerce and Management, 51-65.

[8] Gruman, J. A., \& Saks, A. M. (2013). Organizational socialization and newcomers' psychological capital and wellbeing. Advances in Positive Organizational Psychology, 211236.

[9] He, H., Wang, W., Zhu, W., \& Harris, L. (2015). Service workers' job performance: The role of personality traits, organizational identification and customer orientation. European journal of marketing, 1751-1776.

[10] Kappagoda, S., Hohd.Zainul, O. F., \& Alwis, G. D. (2014). The impact of psychological capital on job performance. European Journal of Business and Management, $143-154$.

[11] Karanika- Murray, M., Dunkan, N., Pontes, H. M., \& Griffiths, M. D. (2015). Organizational identification, work engagement, and job satisfaction. Journal of Managerial Psychology, 1019-1033. 
[12] Murray, M. K., Duncan, N., Pontes, H. M., \& Griffiths, M. D. (2015). Organizational Identification, Work Engagement, and Job Satisfaction. Managerial Psychology, 1019 - 1033.

[13] Rani, H., Arain, G. A., Kumar, A., \& Shaikh, I. R. (2017). Interplay between trust and distrust in the work place: examining the effect of psychological contract breach on organizational disidentification. Journal of Asia Business Studies, 1 - 29.

[14] Razali, M. N., \& Wah, B. Y. (2011). Power Comparison of Shapiro-Wilk,Komogorov-Smirnov, Lilliefors and Anderson-Darling Test. Journal of Statistical Modeling and Analytics.

[15] Rehman, S. U., Yasir, Q., \& Iqbal, L. P. (2017). Impact of psychological capital on occupational burnout and performance of faculty members. International Journal of Educational Management, 1 - 12.

[16] Sapyaprapa, S., Tuicomepee, A., \& Watakakosol, R. (2013). Validation of psychological capital questionnaire in Thai employees. The Asian Conference on Psychology \& the Behavioral Science 2013.

[17] Saunders, M., Lewis, P., \& Thornhill, A. (2009). Research Methods for Methods for Business Students. England: Pearson Education Limited.

[18] Sekaran, U. (2003). Research Methods for Business. New York: Hermitage Publishing Services.

[19] Sekaran, U., \& Bougie, R. (2013). Research Methods for Business.

[20] Sunders, M., Lewis, P., \& Thornhill, A. (2009). Research methords for bussiness students. London: Pitman Publishing.

[21] Tosti- Kharas, J. (2012). Continued organizational identification following involuntary job loss. Managerial Psychology, 1047-1055.

[22] Tuzun, I., Cetin, F., \& Baism, H. (2018). Improving job performance through identification and psychological capital. International Journal of Productivity and Performance Management, 33 - 47.

[23] Xu, J., Liu, Y., \& Chung, B. (2016). Leader psychological capital and employee work engagement. Leadership and Organization Development Journal. 
